\title{
PENGEMBANGAN TAHAPAN KLASIFIKASI APEL ENVY DAN PASIFIC ROSE MENGGUNAKAN JARINGAN SARAF TIRUAN (JST)
}

\author{
Farah Zakiyah Rahmanti*, Prajanto Wahyu Adi, Ion Ataka, Septian Enggar Sukmana \\ Program Studi Teknik Informatika, Fakultas Ilmu Komputer, Universitas Dian Nuswantoro \\ *Corresponding author, e-mail : farah_zakiyah@dsn.dinus.ac.id
}

\begin{abstract}
Abstrak - Jenis apel yang beragam dan beberapa diantaranya memiliki kemiripan membuat persepsi pandang manusia sulit membedakan jenis-jenis apel tertentu. Cara konvensional yang sering dilakukan adalah penilaian subyektif dari persepsi pandang manusia. Penilaian subyektif tersebut bisa menghasilkan pengelompokan jenis apel yang kurang tepat. Teknik pengenalan jenis apel berbasis teknologi informasi menjadi salah satu langkah untuk membantu pengelompokan jenis apel supaya lebih tepat dan akurat serta lebih meringankan tugas manusia pada bidang pengolahan hasil perkebunan apel. Penelitian ini bertujuan untuk mengembangkan tahapan klasifikasi apel envy dan pasific rose. Tujuan utamanya adalah mengklasifikasi buah apel jenis envy dan pasific rose dengan menggunakan Jaringan Saraf Tiruan (JST) atau sering disebut dengan Artificial Neural Network (ANN). Citra apel terlebih dahulu dilakukan ekstraksi fitur yang unik dari citra latih dan citra uji, agar citra tersebut dapat dikenali. Salah satu cara ekstraksi fitur adalah dengan menggunakan pendekatan statistik dari histogram warna RGB sebuah citra. Nilai-nilai yang bisa diambil dari histogram warna RGB citra apel adalah nilai rerata intensitas, standar deviasi, skewness, energi, entropi, dan smoothnes. Kemudian nilai-nilai tersebut sebagai nilai masukan untuk tahapan klasifikasi menggunakan JST feed-forward backpropagation. Hasil pengujian dibagi menjadi tiga skenario, pertama dengan data latih 50 data uji 10 memiliki nilai akurasi sebesar $80 \%$. Skenario pengujian kedua dengan data latih 70 data uji 10 memiliki nilai akurasi sebesar $80 \%$. Skenario pengujian ketiga dengan data latih 90 data uji 10 memiliki akurasi sebesar $90 \%$. Hasil pengujian tersebut menunjukan bahwa nilai akurasi tertinggi terletak pada pengujian ketiga.
\end{abstract}

Kata Kunci : Apel, Ekstraksi fitur, Jaringan saraf tiruan, Backpropagation

\begin{abstract}
The variety of apple has similarity with each other, therefore it makes human visual perception difficult to differentiate some of them. The conventional way is often carried out human vision subjective perception, this way makes classification result becomes less. Apple classification using information technology is one step to classify apple more accurate and to help human in apple plantations processing. The goal of this research is developing classification stage on envy and pasific rose apple. The major goal is to classify envy and pacific rose apple using Artificial Neural Network (ANN). Doing feature extraction of training and testing apple images aims that images can be recognized as envy or pasific rose. The way of getting feature extraction is using statistical approach of RGB color histogram from an image. The feature extraction values of RGB color histogram of apple images are intensity, standard deviation, skewness, energy, entropy, and smoothness. Then, those values as an input of classification step using ANN feedforward backpropagation. The results of this research are consists of three scenario of experiment, first skenario is using 50 training data 10 testing data, it has accuracy value $80 \%$. Second scenario is using 70 training data 10 testing data, it also has accuracy value 80\%. Third scenario is using 90 training data 10 testing data, it has accuracy value $90 \%$. This experiment result shows that the highest accuracy value is in third scenario.
\end{abstract}

Keywords : Apple, Feature extraction, Artificial neural network, Backpropagation

Copyright $\odot 2016$ JNTE. All rights reserved

\section{PENDAhUluan}

Pengolahan hasil perkebunan apel pada saat ini sudah berkembang pesat. Hal ini dikarenakan sudah banyak industri yang menggunakan teknologi canggih dalam proses pengolahannya. Salah satu tahapan yang ada dalam proses pengolahan hasil perkebunan apel adalah pengelompokan hasil perkebunan yakni buah apel berdasarkan jenisnya. Pengelompokan buah apel biasanya ditentukan oleh beberapa parameter, diantaranya adalah ukuran, berat, ciri warna, keharuman, dan masih banyak lagi lainnya [1]. Pengelompokan buah apel dari sisi 
warna kulit buah merupakan salah satu faktor penting dalam mengidentifikasi jenis apel.

Pada tahapan tersebut biasanya sangat bergantung pada persepsi mata manusia terhadap faktor komposisi warna. Persepsi mata manusia biasanya cenderung subyektif terhadap suatu obyek dalam melakukan pengelompokan. Contohnya sesuai pada Gambar 2 merupakan contoh dari apel envy dan pasific rose, dengan kemampuan mata manusia akan terlihat sangat mirip bahkan susah dalam membedakannya.

Perkembangan teknologi dan ilmu pengetahuan pada citra digital memungkinkan untuk melakukan pengelompokan secara otomatis dengan menggunakan komputer. Oleh karena itu, diperlukan sebuah sistem yang dapat melakukan pemilihan buah apel berdasarkan jenis - jenisnya yang dilakukan secara otomatis.

Teknik pengelompokan secara otomatis menggunakan teknologi komputer biasa disebut teknik klasifikasi. Klasifikasi biasa dilakukan melalui fitur-fitur yang diolah dengan menerapkan langkah-langkah pengumpulan dan pengelompokan data dengan beberapa upaya seperti pembagian ukuran fitur, seleksi fitur, dan pendesainan klasifikasi berdasar aturan (rulebased) [3]. Secara praktikal, salah satu contoh bentuk pengolahan fitur dapat dilakukan melalui ekstraksi warna R-B [9].

Pada penelitian sebelumnya yang telah dilakukan oleh Ion (2015) tentang identifikasi dari buah apel menggunakan K-Nearest Neighbor (KNN) dan pendekatan jaraknya dengan Minkowski yang memiliki tingkat akurasi sebesar 90\% [6].

Pengembangan tahapan klasifikasi dari penelitian sebelumnya bertujuan agar dapat meningkatkan tingkat akurasi, meskipun dalam penelitian sebelumnya sudah memiliki cukup tinggi akurasinya dalam mengidentifikasi buah apel.

Penelitian ini bertujuan untuk mengidentifikasi buah apel envy dan apel pasific rose dengan menggunakan Artificial Neural Network (ANN). Citra buah apel dilakukan ekstraksi fitur dengan mendapatkan histogram warna RGB, kemudian dari nilai histogram tersebut akan didapatkan beberapa fitur seperti rerata intensitas, standar deviasi, skewness, energi, entropi, dan smoothness. Nilai-nilai itulah yang akan dijadikan nilai masukan pada tahapan klasifikasi.

\section{DATA PENELITIAN}

Citra masukan yang digunakan dalam penelitian ini adalah citra buah apel jenis envy dan pasific rose. Jenis data yang digunakan terdiri dari data primer dan data sekunder. Data primer diambil melalui pemotretan objek apel envy dan pacific rose menggunakan kamera DSLR (Gambar 1). Sedangkan data sekunder diambil dari beberapa direktori penyedia data terbuka seperti SCIEN (The Stanford Center for Image Systems Engineering), CIFAR-10, dan CASC IFW (The Coalition for Academic Scientific Computation).

Pada saat pengambilan data primer, alat utama yang digunakan adalah kamera DSLR dengan lensa 18-55 mm, sedangkan bahan yang digunakan adalah objek apel yang digunakan untuk penelitian yaitu apel jenis envy dan pacific rose. Teknik pengambilan data dilakukan dengan peletakan kamera pada ketinggian $50 \mathrm{~cm}$ menggunakan tripod dan kemiringan $30^{\circ} \mathrm{ke}$ bawah. Lensa kamera diatur pada setting $35 \mathrm{~mm}$ ISO 400 diafragma $f / 6.3$. Latar belakang dengan kertas A4 80 gsm berwarna putih sebanyak dua lembar.

Berdasarkan pemanfaatan data, terdapat dua jenis data yang digunakan pada penelitian ini, yaitu citra sebagai data latih (training data) sejumlah 90 citra dan citra sebagai data uji (testing data) sejumlah 10 citra.

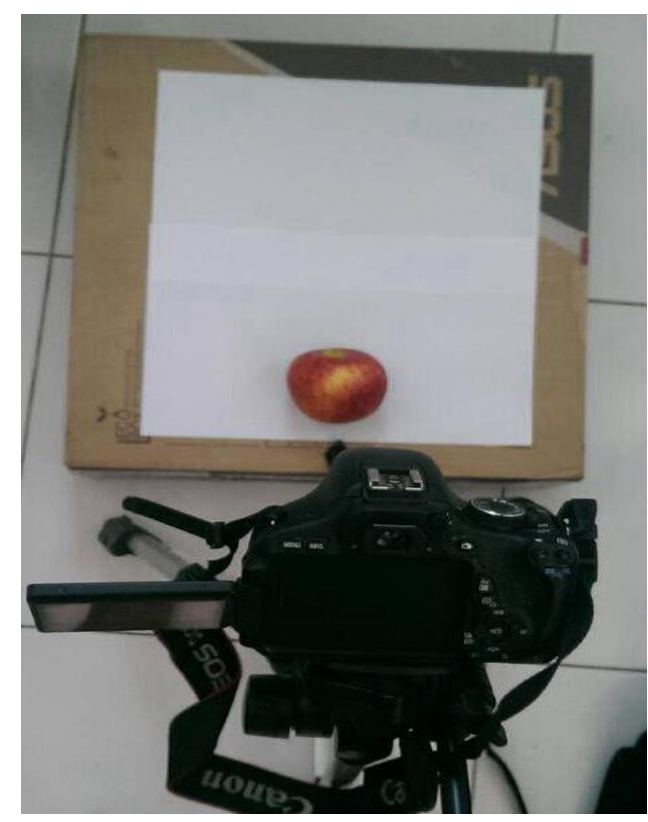

Gambar 1. Pengambilan Citra Apel 


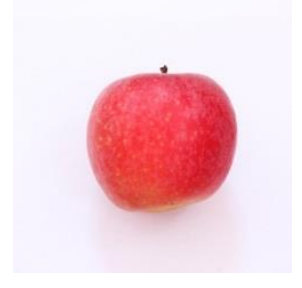

(a)

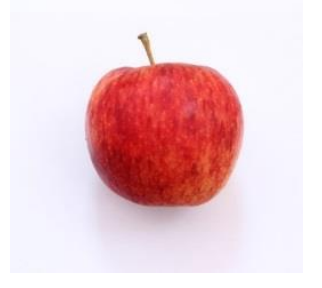

(b)
Gambar 2. (a) Contoh Apel Envy

(b) Contoh Apel Pasific Rose

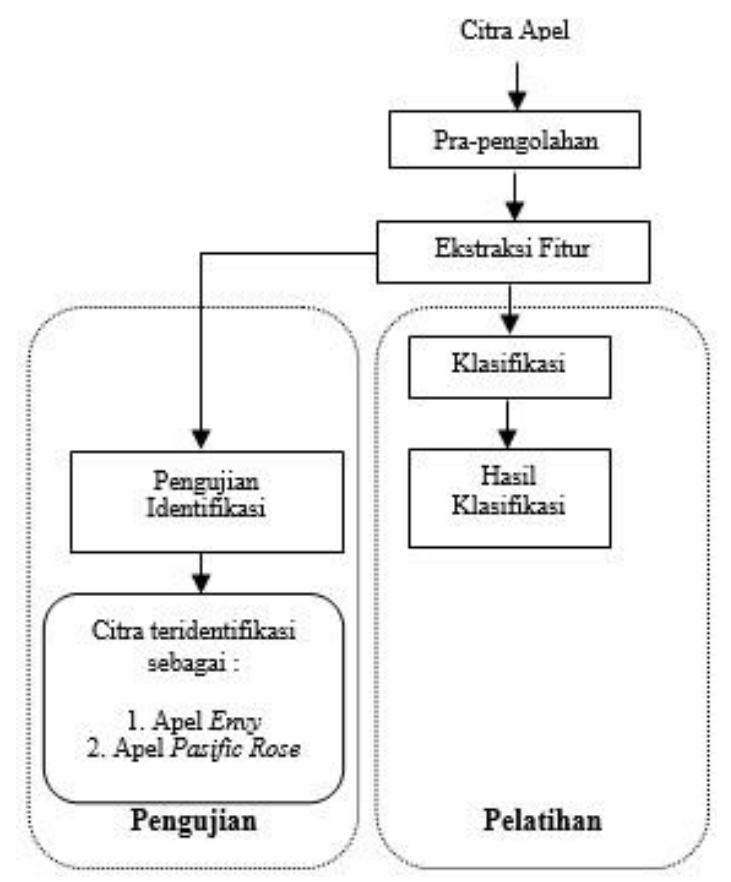

Gambar 3. Blok Diagram Sistem

\section{METODE PENELITIAN}

Data penelitian yang didapat masih perlu dilakukan pra-pengolahan citra, agar memperoleh hasil yang sesuai dengan kebutuhan. Citra apel dilakukan normalisasi ke dalam dimensi $625 \times 417$ piksel.

Tahap selanjutnya adalah mendapatkan ciri unik dari citra apel dengan cara memperoleh histogram RGB dari masing-masing citra tersebut. Dari histogram inilah akan didapatkan nilai-nilai statistik seperti rerata intensitas, standar deviasi, skewness, energi, entropi, dan smoothness.

Hasil ekstraksi fitur berupa nilai-nilai statistik tadi sebagai input untuk tahap klasifikasi citra. Metode klasifikasi yang digunakan dalam penelitian ini yaitu menggunakan Jaringan Saraf Tiruan (JST) atau sering disebut juga Artificial Neural Network (ANN) dengan model pelatihan Feed Forward Backpropagation. Hasil akhir dari penelitian ini adalah citra apel dapat teridentifikasi menurut jenisnya. Tahapan - tahapan penelitian terilustrasi pada blok diagram sistem penelitian seperti pada Gambar 3.

\section{EKSTRAKSI FITUR}

Ekstraksi fitur adalah sebuah proses untuk mendapatkan ciri unik dari suatu obyek sehingga obyek tersebut dapat dikenali. Pada kegiatan yang dilakukan, teknik pendekatan warna dilakukan agar ciri yang menonjol dari warna apel envy dan apel pasific rose didapatkan. Pendekatan ekstraksi fitur pada kegiatan ini adalah pendekatan statistik dengan mengambil nilai rerata intensitas, standar deviasi, skewness, energi, entropi, dan smoothness dari histogram warna RGB citra apel.

Fitur yang pertama adalah nilai rerata intensitas dan disimbolkan dengan $m$ yang ditunjukkan pada persamaan (1).

$$
m=\sum_{i=0}^{L-1} i \cdot p(i)
$$

$i$ merupakan aras keabuan pada citra $f$ dan $p(i)$ merupakan probabilitas kemunculan $i$. $L$ merupakan nilai aras keabuan tertinggi. Hasil pada persamaan (1) adalah rerata kecerahan pada citra.

Fitur yang kedua adalah standar deviasi yang ditunjukkan pada persamaan (2). $\sigma^{2}$ merupakan varians / momen orde dua ternormalisasi sebagai akibat $p(i)$ dinyatakan sebagai fungsi peluang. Fitur ini menghasilkan ukuran kekontrasan.

$$
\sigma=\sqrt{\sum_{i=0}^{L-1}(i-m)^{2} p(i)}
$$

Fitur yang ketiga adalah skewness, sering disebut juga momen orde tiga ternormalisasi. Fitur ini menunjukkan nilai negatif yang menyatakan bahwa distribusi pada kecerahan lebih condong ke kanan terhadap rerata. Nilai skewness dibagi menjadi $(L-1)^{2}$ agar lebih ternormalisasi. Skewness ditunjukkan pada persamaan (3).

$$
\text { Skewness }=\sum_{i=1}^{L-1}(i-m)^{3} p(i)
$$


Fitur keempat adalah energi yang ditunjukkan pada persamaan (4). Energi merupakan ukuran yang menyatakan distribusi intensitas piksel pada jangkauan aras keabuan. Citra yang sama dengan satu nilai aras keabuan akan mempunyai nilai energi yang maksimum, yaitu sebesar 1. Secara umum, citra dengan sedikit aras keabuan akan mempunyai energi yang lebih tinggi daripada citra yang mempunyai banyak nilai aras keabuan. Energi sering disebut juga sebagai keseragaman.

$$
\text { energi }=\sum_{i=0}^{L-1}[p(i)]
$$

Fitur yang kelima adalah entropi yang mengindikasikan kompleksitas citra dan ditunjukkan pada persamaan (5). Semakin tinggi nilai entropinya maka akan semakin kompleks citra tersebut. Entropi serta energi berkecendungan berkebalikan. Entropi juga merepresentasikan jumlah informasi yang terkandung pada sebaran data.

$$
\text { entropi }=\sum_{i=0}^{L-1} p(i) \log _{2}(p(i))
$$

Fitur yang terakhir adalah fitur kehalusan (smoothness). Fitur ini bertujuan untuk mengukur tingkat kehalusan atau kekasaran intensitas citra dan ditunjukkan pada persamaan (6). Nilai pada $R$ rendah menunjukan bahwa citra memiliki intensitas yang kasar.

$$
R=1-\frac{1}{1+\sigma^{2}}
$$

Enam fitur yang diperoleh akan diolah menggunakan metode JST. Metode JST yang digunakan pada penelitian ini berfungsi untuk klasifikasi penentuan jenis apel sehingga dalam hal ini, hasil dari pengolahan fitur-fitur oleh JST digunakan sebagai penentuan objek apel yang dievaluasi masuk pada jenis envy atau pacific rose.
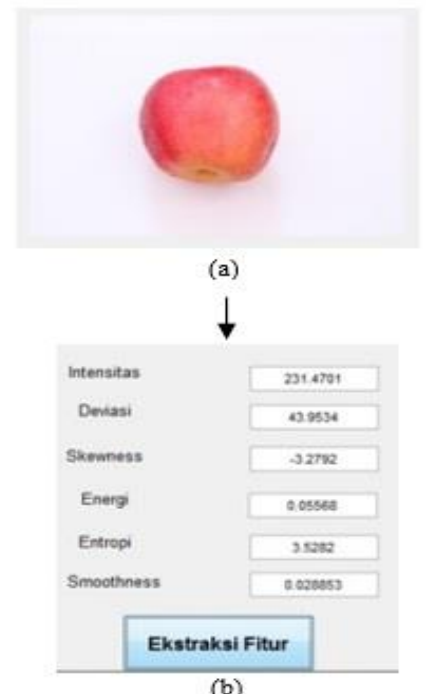

Gambar 4. (a) Citra Apel

(b) Nilai Ekstraksi Fitur dari Citra Apel (a)

\section{KLASIFIKASI}

Jaringan Saraf Tiruan (JST) atau sering juga dikenal dengan nama Artificial Neural Network (ANN) merupakan salah satu komponen yang ada pada komputasi lunak (soft computing) dengan meniru sistem saraf manusia [8]. Dari segi fungsi, JST ditujukan untuk merancang suatu komputer sehingga dapat difungsikan untuk melakukan proses pelatihan dari suatu contoh. Sedangkan dari struktur rancangan, JST adalah suatu alat penghitung yang ditujukan untuk dapat melakukan proses serupa dengan apa yang dapat dilakukan manusia [5][7].

Pembelajaran JST berupa perubahan bobot yang terdapat dalam arsitektur JST, dimana noda-noda input dan bobot-bobot tersebut saling terhubung satu sama lain [4].

Jenis metode JST yang digunakan pada penelitian ini adalah Feed Forward Backpropagation. Jenis metode ini merupakan pelatihan data yang terawasi (supervised),

Tabel 1. Contoh Ekstraksi Fitur dari Lima Data Pelatihan

\begin{tabular}{|c|c|c|c|c|c|c|}
\hline Nama Gambar & Intensitas & Deviasi & Skewness & energi & entropi & smoothness \\
\hline 1.jpg & 228,895 & 52,680 & $-6,177$ & 0,055 & 3,596 & 0,040 \\
\hline 2.jpg & 229,783 & 42,932 & $-3,076$ & 0,045 & 3,722 & 0,027 \\
\hline 3.jpg & 224,403 & 58,450 & $-7,943$ & 0,052 & 3,668 & 0,049 \\
\hline 4.jpg & 228,240 & 49,623 & $-5,029$ & 0,052 & 3,653 & 0,036 \\
\hline
\end{tabular}


selain itu pelatihan tersebut digunakan oleh perceptron dengan banyak lapisan (layer) untuk mengubah bobot-bobot yang terhubung dengan neuron yang berada di dalam lapisan tersembunyi (hidden layer). Ciri khas dari metode feed forward backpropagation adalah penggunaan nilai keluaran (output) yang error untuk mengubah nilai bobot secara mundur (backward) [2].

Gambar 5 menunjukkan skema metode JST yang secara khusus digunakan pada penelitian ini. Terdapat tiga buah layer yaitu layer masukan, layer tersembunyi, dan layer keluaran.

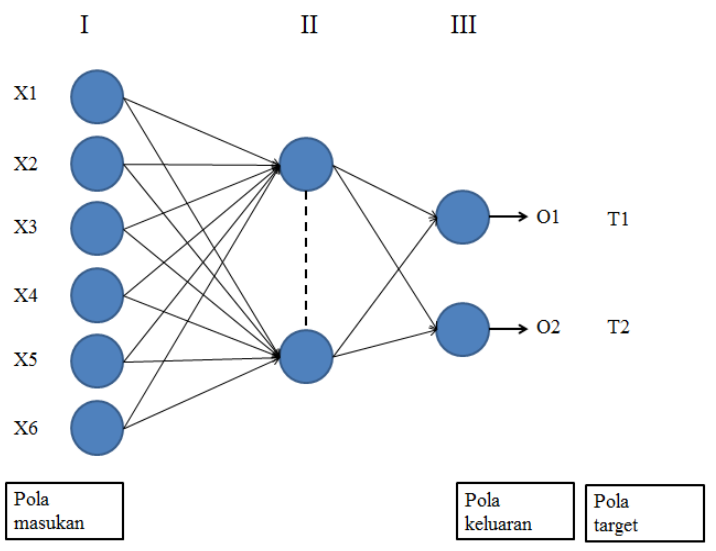

Gambar 5. Struktur Jaringan Saraf Tiruan (JST)

Parameter masukan $\left(x_{1}, x_{2}, x_{3}, x_{4}, x_{5}, x_{6}\right)$ merupakan fitur-fitur yang diperoleh dari tahap ekstraksi fitur, setiap $x_{n}$ menunjukkan identitas dari setiap fitur, $x_{1}$ merupakan parameter dari fitur rerata, $x_{2}$ merupakan parameter standar deviasi, $x_{3}$ merupakan parameter skewness, $x_{4}$ merupakan parameter energi, $x_{5}$ merupakan parameter entropi, $x_{6}$ merupakan parameter smoothness.

\section{HASIL DAN PEMBAHASAN}

Pada bagian ini dibahas dan dievaluasi efektifitas metode pengembangan klasifikasi yang digunakan dalam penelitian ini.

Pengujian dilakukan dengan tiga skenario percobaan, diantaranya skenario pertama 50 data latih 10 data uji, skenario kedua 70 data latih 10 data uji, dan skenario ketiga 90 data latih 10 data uji. Hasilnya sesuai pada Tabel 2. Parameter uji coba yang digunakan adalah :

1. Tipe citra : JPG/JPEG

2. Ukuran citra : $625 \times 417$ piksel
3. Metode JST :

4. Feed-forward Backpropagation

5. Training function: Lavenberg-Marquardt

6. Adaptation learning function : Gradient Descent

7. Performance function: MSE

8. Jumlah layer : 3

9. Jumlah neuron masukan : 5

10. Transfer function: sigmoid bipolar

11. Learning rate $(\mathrm{mu}): 0,001$

12. Epoch : 2000

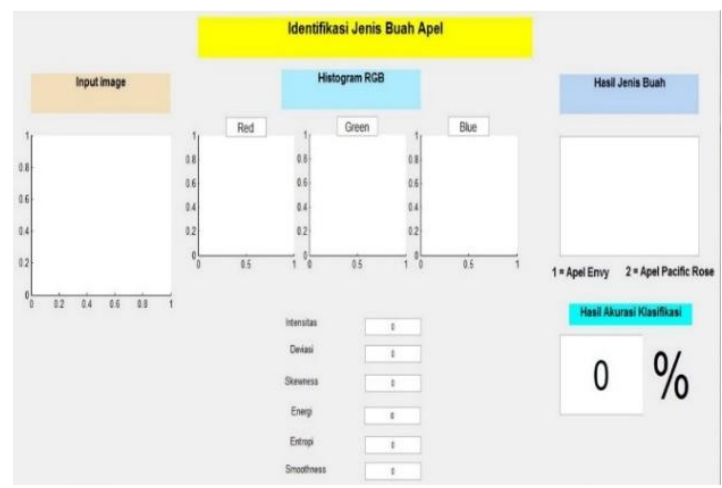

Gambar 6. Screenshoot Prototipe Aplikasi Identifikasi Buah Apel

Tabel 2. Hasil Percobaan dan Hasil Akurasi

\begin{tabular}{|c|c|c|c|}
\hline No & $\begin{array}{c}\text { Jumlah } \\
\text { Data Latih }\end{array}$ & $\begin{array}{c}\text { Jumlah } \\
\text { Data Uji }\end{array}$ & $\begin{array}{c}\text { Hasil } \\
\text { Akurasi }\end{array}$ \\
\hline 1 & 50 & 10 & $80 \%$ \\
\hline 2 & 70 & 10 & $80 \%$ \\
\hline 3 & 90 & 10 & $90 \%$ \\
\hline
\end{tabular}

Hasil pengujian dari prosees klasifikasi yang telah dilakukan menggunakan JST feed-forward backpropagation dengan data latih 50 dan data uji 10, maka didapatkan nilai akurasi sebesar $80 \%$ dan hasil pengujiannya sesuai pada Tabel 2 .

Tabel 2. Hasil Pengujian dengan Data Latih 50 Data Uji 10

\begin{tabular}{|c|c|c|c|}
\hline No & Nama & Hasil klasifikasi & Keterangan \\
\hline 1 & $1 . j p g$ & Apel envy & True \\
\hline 2 & $2 . j p g$ & Apel envy & True \\
\hline 3 & $3 . j p g$ & Apel envy & True \\
\hline 4 & $4 . j p g$ & Apel pasicif Rose & False \\
\hline 5 & 5.jpg & Apel pasicif Rose & False \\
\hline 6 & $6 . j p g$ & Apel pasific rose & True \\
\hline 7 & 7.jpg & Apel pasific rose & True \\
\hline 8 & 8.jpg & Apel pasific rose & True \\
\hline 9 & $9 . j p g$ & Apel pasific rose & True \\
\hline 10 & 10.jpg & Apel pasific rose & True \\
\hline
\end{tabular}


Hasil pengujian dari proses klasifikasi yang telah dilakukan menggunakan JST feed-forward backpropagation dengan data latih 70 dan data uji 10, maka didapatkan nilai akurasi sebesar $80 \%$ dan hasil pengujiannya sesuai pada Tabel 3 .

Tabel 3. Hasil Pengujian dengan Data Latih 70 Data Uji 10

\begin{tabular}{|c|c|c|c|}
\hline No & Nama & Hasil klasifikasi & Keterangan \\
\hline 1 & $1 . j p g$ & Apel envy & True \\
\hline 2 & $2 . j p g$ & Apel envy & True \\
\hline 3 & $3 . j p g$ & Apel envy & True \\
\hline 4 & $4 . j p g$ & Apel pasicif Rose & False \\
\hline 5 & $5 . j p g$ & Apel envy & True \\
\hline 6 & $6 . j p g$ & Apel pasific rose & True \\
\hline 7 & $7 . j p g$ & Apel pasific rose & True \\
\hline 8 & $8 . j p g$ & Apel pasific rose & True \\
\hline 9 & $9 . j p g$ & Apel envy & False \\
\hline 10 & $10 . j p g$ & Apel pasific rose & True \\
\hline
\end{tabular}

Hasil pengujian dari prosees klasifikasi yang telah dilakukan menggunakan JST feed-forward backpropagation dengan data latih 90 dan data uji 10, maka didapatkan nilai akurasi sebesar 90\% dan hasil pengujiannya sesuai pada Tabel 4 .

Tabel 4. Hasil Pengujian dengan Data Latih 90 Data Uji 10

\begin{tabular}{|c|c|c|c|}
\hline No & Nama & Hasil klasifikasi & Keterangan \\
\hline 1 & $1 . j p g$ & Apel envy & True \\
\hline 2 & $2 . j p g$ & Apel envy & True \\
\hline 3 & $3 . j p g$ & Apel envy & True \\
\hline 4 & $4 . j p g$ & Apel envy & True \\
\hline 5 & $5 . j p g$ & Apel envy & True \\
\hline 6 & $6 . j p g$ & Apel pasific rose & True \\
\hline 7 & $7 . j p g$ & Apel pasific rose & True \\
\hline 8 & $8 . j p g$ & Apel pasific rose & True \\
\hline 9 & $9 . j p g$ & Apel envy & False \\
\hline 10 & $10 . j p g$ & Apel pasific rose & True \\
\hline
\end{tabular}

\section{KESIMPULAN}

Pada penelitian ini telah dikembangkan tahapan klasifikasi menggunakan JST feedforward backpropagation dan ekstraksi fitur pendekatan statistik dari histogram warna RGB citra apel menghasilkan nilai rerata intensitas, standar deviasi, skewness, energi, entropi, dan smoothness.

Hasil pengujian dari proses klasifikasi yang telah dilakukan menggunakan ANN dengan data latih dan data uji masing-masing 50 dan 10 dengan nilai akurasi sebesar $80 \%$. Pengujian kedua dengan data latih dan data uji masing- masing 70 dan 10 dengan nilai akurasi sebesar $80 \%$. Pengujian ketiga dengan data latih dan data uji masing-masing 90 dan 10 dengan nilai akurasi sebesar $90 \%$.

Hasil pengujian menunjukkan bahwa nilai akurasi tertinggi terletak pada pengujian ketiga yakni dengan data uji 90 data latih 10. Selain itu, berdasarkan hasil pengujian menunjukkan bahwa citra 4.jpg, 5.jpg, dan 9.jpg memiliki kedekatan nilai ekstraksi fiturnya. Sehingga, sistem bisa benar / salah dalam mengidentifikasi jenis buah apel.

Penelitian lanjutan dapat dikembangkan menggunakan metode klasifikasi lainnya yang dapat meningkatkan akurasi identifikasi jenis buah apel. Selain itu, penelitian lanjutan juga dapat menggunakan data yang lebih bervariasi seperti citra dari jenis buah apel lainnya yang memiliki beberapa kemiripan dengan apel envy dan apel pasific rose.

\section{DAFTAR PUSTAKA}

[1] Andri, Paulus, N. W., Wong \& T. Gunawan, Segmentasi Buah Menggunakan Metode K-Means Clustering dan Identifikasi Kematangannya Menggunakan Metode Perpandingan Kadar Warna, vol 15, (2014).

[2] Austeclino, M.B.J., Angelo, A.D., Manoel, B.N., Artificial Neural Network and Bayesian Network As Supporting Tools for Diagnosis of Asymptomatic Malaria, 978-1-4244-6376-3/10/\$26.00, IEEE, 2010.

[3] Calvin Hung, Zhe Xu, Salah Sukkarieh, Feature Learning Based Approach for Weed Calssification Using High Resolution Aerial Images from a Digital Camera Mounted on a UAV, Remote Sensing, 2014.

[4] Fajar Budiman, Muhammad A., Muhammad R., \& Suwito, Pengenalan Suara Burung Menggunakan Mel Frequency Cepstrum Coefficient dan Jaringan Syaraf Tiruan pada Sistem Pengusir Hama Burung, Jurnal Nasional Teknik Elektro (JNTE) Vol 5 No 1, (2016).

[5] Farah Z.R., Identifikasi Parasit Malaria pada Think Blood Film Menggunakan Artificial Neural Network (ANN), 
Jurusan Teknik Elektro, Institut Teknologi Sepuluh Nopember (ITS) Surabaya (2013).

[6] Ion A. H., Identifikasi Jenis Buah Apel Menggunakan Algoritma K-Nearest Neighbor (KNN) dengan Ekstraksi Fitur Histogram, Jurusan Teknik Informatika, Universitas Dian Nuswantoro Semarang (2015).

[7] Mauridhi, H.P., Agus, K., Supervised Neural Network dan Aplikasinya, Graha Ilmu Yogyakarta, (2006).

[8] Robert E. Uhrig, Introduction to Artificial Neural Network, Proceedings of the 1995 IEEE IECON 21st Vol. 1, (1995).

[9] Wei J., Xiangli M., Yun T., Bo X., Dean Z., Fast Segmentation of Colour Apple Image under All-weather Natural Conditions for Vision Recognition of Picking Robots. International Journal of Advanced Robotic Systems, (2016).

\section{Biodata Penulis}

Farah Zakiyah Rahmanti, lahir di Surabaya tanggal 15 Desember 1987, berhasil menyelesaikan program D4 Teknik Informatika tahun 2010 di Politeknik Elektronika Negeri Surabaya (PENS) - Institut Teknologi Sepuluh Nopember (ITS) Surabaya. Kemudian menyelesaikan program Magister Teknik Elektro konsentrasi Jaringan Cerdas Multimedia (JCM) tahun 2013 di Institut Teknologi Sepuluh Nopember (ITS) Surabaya. Tahun 2014 hingga saat ini menjadi dosen Teknik Informatika Fakultas Ilmu Komputer di Universitas Dian Nuswantoro (UDINUS) Semarang. 